\title{
O ROMANCE PLURILINGUE OU COMO A LÍNGUA INCORPORA A CULTURA DO OUTRO
}

\author{
(The multilingual novel or how language includes \\ the Other's culture)
}

\author{
Isabelle Simões Marques ${ }^{1}$ \\ (Universidade de Coimbra - UC, Portugal)
}

\begin{abstract}
The languages, while "codes" are instruments of socio-political, socioeconomic and socio-cultural challenges. The discursive heterogeneity accompanies miscegenation and cultural identity in these multilingual novels. This multilingual writing, with cultural and linguistic sources, allows the construction of a "meta-narrative identity" and draws attention to the notion of linguistic identity. The multilinguism in novels isn't merely an enactment of the word of the Other as opposed to a specific language that ensures the identity of the speaker, and can also function as a movement of relativization for identity criteria membership.

Multilingualism in novels works as a centrifugal force that allows the decentralization and break of the Portuguese State's monolingual and centered speech. These novels are an example of the deconstruction in dominant models of identity as they portray characters which represent peripheral ethnic groups.
\end{abstract}

Keywords: Multilinguism, contemporary portuguese novel, identity, alterity, culture

1. Isabelle Simões Marques é Leitora de francês na Faculdade de Letras da Universidade de Coimbra, Portugal. Pertence ao Laboratoire d'Études Romanes da Université Paris 8 (França) e ao Centro de Linguística da Universidade Nova de Lisboa (Portugal). Em 2009, concluiu a sua Tese de Doutoramento - em cotutelacom o título seguinte: "Le plurilinguisme dans le roman portugais contemporain (1963-1983): configurations linguistiques et textuelles”. Já publicou vários artigos e participou em diversos congressos na área da linguística e da literatura. Os seus domínios de interesse prendem-se com questões ligadas à identide, à alteridade e ao plurilinguismo literário e linguístico. 


\section{RESUMO}

As línguas, enquanto "códigos", são instrumentos de desafios sóciopolíticos, sócio-económicos e sócio-culturais. A heterogeneidade discursiva acompanha a miscigenação identitária e cultural presente nos romances plurilingues. Esta escrita plurilingue, com fontes culturais e linguísticas diversas, permite a construção de uma "meta-narrativa identitária" e chama a atenção para a noção de identidade linguística. O plurilinguismo nos romances não funciona apenas como uma mera encenação da palavra do Outro em oposição a uma língua específica que garanta a identidade do locutor, mas sim como um movimento de relativização dos critérios de pertença identitária. O plurilinguismo, presente nos romances, representa uma força centrífuga que permite descentrar e quebrar o discurso monolingue e centralizado do Estado Português. Os romances são um exemplo da desconstrução de modelos identitários dominantes e retratam personagens, representando grupos étnicos periféricos.

Palavras-chave: plurilinguismo, romance português contemporâneo, identidade, alteridade, cultura

\section{Literatura e língua}

O interesse em analisar um corpus literário prende-se com o facto de considerarmos que a literatura tem como principal ferramenta a língua. Qualquer língua de escrita constitui uma construção dentro da língua comum.

A questão do exílio acompanha uma grande parte da história social, política e literária de Portugal nos séculos XIX e XX. Vários estudos abordam a questão de um ponto de vista social (Costa, 1996), político (Soares, 1975) e literário (Machado, 1980, e Seabra, 2002). Diferentes escritores passaram pela experiência de viver no estrangeiro por razões políticas (ou não), mas, durante esse tempo, mantiveramse sempre ligados à língua portuguesa. Esta literatura de emigração ou de "diáspora" corresponde a certo tipo de obras escritas por autores que vive(ra)m no exterior mas que publica(ra)m em Portugal e que escreve(ra)m em português (Cravo e Heitor, 1983, e Capinha, 1993). 
Este é o cenário que escolhemos para analisar. Alguns autores decidiram manter a língua portuguesa como língua matriz da sua escrita. Apesar da experiência do exílio - e, portanto, do contacto com a alteridade e o estrangeiro - os escritores optaram por manter a sua primeira língua nas suas obras. No entanto, se a língua portuguesa é a língua matriz dos autores, é inegável que estes foram marcados pela sua experiência no exterior e, consequentemente, incorporam em filigrana marcas ou particularidades das línguas europeias ou africanas na sua escrita. Estas diferentes experiências de vida afetaram profundamente os autores que, pelo seu estatuto, se tornaram conscientes da sua alteridade. Esta é, aliás, uma característica comum a todos os autores que, de diversas formas, recorrem ao plurilinguismo literário.

Como é apontado por Arnaldo Saraiva (1977: 17), o plurilinguismo torna mais complexas e flexíveis as manifestações de pensamento e de emoção e, como tal, confere uma profundidade mais precisa aos conceitos que geralmente são concebidos de uma forma mais abstrata e expressos de uma forma mais vaga. $\mathrm{O}$ confronto, o cruzamento das línguas e os seus efeitos são notáveis na literatura moderna. A prática do bilinguismo ou do plurilinguismo deve ser considerada como um dos elementos fundamentais para a caraterização da literatura de avant-garde que ocorreu no início do século XX (por exemplo James Joyce, Ezra Pound ou Fernando Pessoa). Podemos falar literalmente de bilinguismo ou plurilinguismo simbólico, uma vez que, no que diz respeito à literatura, Roland Barthes (1970: 127) afirma que "le texte est d'emblée, en naissant, multilingue" (pt. O texto é logo à partida, ao nascer, multilingue). Em $S / Z$, Roland Barthes discute os diferentes códigos linguísticos que estão presentes ao longo do texto.

Para Arnaldo Saraiva (1977: 93), o bilinguismo intertextual é uma pesquisa individual de uma visão diferente do mundo:

Quanto ao bilinguismo intertextual, o que ele põe em jogo não são só dois "estilos" ou duas "estilísticas", mas duas ideologias, duas visões do mundo, duas conceções diferenciadas da vida. Todavia, a prática do bilinguismo intertextual pode ter que ver menos com a obtenção de uma determinada visão do mundo do que com o/ um desejo de uma 
visão do mundo outra; menos com uma necessidade de comunicação ou prestígio social do que com uma busca individual.

O desafio não é entender a escolha de uma segunda língua, mas sim tentar compreender por que razão uma língua em particular se revelou insuficiente aos olhos do escritor, "No fundo, talvez seja sempre uma terceira língua, uma terceira língua, que os escritores e os homens bilingues buscam: uma língua ou uma língua simultaneamente mais pessoal e mais universal”. (Saraiva, 1977: 97)

A presença de escritores que tiveram a experiência da alteridade ao longo do seu percurso permite-nos questionar, de acordo com os termos de Édouard Glissant (1997), o seu lugar no mundo da literatura e perguntar a que literatura pertencem, se é à literatura portuguesa, francesa, americana ou à literatura "tout-monde" (pt. "todo-mundo")?

Segundo Arnaldo Saraiva (1977: 12), os escritores pertencem apenas à língua que tem a característica de ser universal, "O único critério que parece decisivo para a inclusão de um escritor numa literatura só pode ser o linguístico, ou o linguístico-literário. (...) Porque no fundo nenhum escritor pertence a nenhuma literatura, língua ou país: pertence apenas à língua, quer dizer, é de toda a humanidade".

Para Lise Gauvin (1997: 7), o escritor depara-se com a reinvenção da língua para criar a sua própria língua de escrita de acordo com o seu público ou a imagem do ou dos destinatário(s) e existe uma "surconscience linguistique" (pt. superconsciência linguística) do escritor que é levado a pensar a língua. Escrever torna-se, desta forma, um verdadeiro ato de fala, visto que a escolha de uma língua em particular é reveladora de um "processo literário” (Gauvin: 1999) que revela o estatuto de uma literatura em particular. A língua literária é construída a partir da língua comum e participa nela de maneira fundamental.

Desta forma, a literatura contribui para o estatuto de uma língua, como o especifica Dominique Maingueneau (2004: 153), "As obras não se contentam de passar pelo canal da língua, mas cada ato 
de enunciação literária, mesmo por mais trivial que seja, reforça a língua mobilizada no seu papel de língua digna de literatura e, para além disso, de língua por si só. A literatura não toma conhecimento de uma hierarquia intangível, mas sim contribui para estabelecê-la, reforçá-la ou enfraquecê-la”"

O código linguístico é verdadeiramente a ferramenta do escritor e Dominique Combe (1995: 108) afirma que cada língua transmite uma "visão de mundo" própria a cada cultura, o facto de mudar de língua leva a ver e a pensar o mundo de forma diferente. Gilles Deleuze (1983: 138) considera que o escritor é sempre um estrangeiro na língua em que se expressa, tal como o afirma Jacques Derrida (1996: 15): « Je n'ai qu'une langue et ce n'est pas la mienne » (pt. Eu só tenho uma língua e não é minha).

Para Julia Kristeva (1997), os escritores são, necessariamente, construtores de línguas e, como o enfatizou Dominique Maingueneau (2004: 139), em qualquer processo criativo, o escritor é forçado a eleger a língua que investe a sua obra, uma língua que, em todo o caso, não pode ser sua ("d'élire la langue qu'investit son œuvre, une langue qui, de toute façon ne peut pas être sa langue”) e, diz o linguista, a propósito das restrições de códigos coletivos (línguas e géneros): "Ele [o escritor] vê impor-se, quando quer produzir literatura, uma língua e códigos coletivos apropriados a géneros de textos apropriados" 3 (Maingueneau, 2004: 140).

É o que o autor classifica de "interlíngua", que é, segundo ele, o diálogo permanente entre diferentes línguas e usos: "O escritor não está confrontado com a língua mas sim com uma interação de línguas e usos"4 (Maingueneau, 2004: 140). Para o autor, o escritor apropria

2. As traduções em português são nossas. « Les œuvres ne se contentent pas de passer par le canal de la langue, mais chaque acte d'énonciation littéraire, si dérisoire qu'il puisse sembler, vient conforter la langue qu'elle mobilise dans son rôle de langue digne de littérature et, au-delà, de langue tout court. Loin de prendre acte d'une hiérarchie intangible, la littérature contribue à la constituer, à la renforcer ou à l'affaiblir ».

3. «Il [1'écrivain] se voit imposer, quand il veut produire de la littérature, une langue et des codes collectifs appropriés à des genres de textes appropriés".

4. « L'écrivain n'est pas confronté à la langue, mais à une interaction de langues et d'usages ». 
a língua que usa dependendo do tipo de texto e da temática. O escritor pode distribuir as suas línguas de acordo com a sua própria economia, a alteridade linguística é um ato literário e político. Apercebemo-nos de que a escrita é um espaço de tensão e de encontro onde o escritor encontra a sua própria língua. De acordo com Henri Meschonnic (1999 : 117), "A literatura é a realização máxima da oralidade, e o é cada vez que atua como uma subjetivação máxima do discurso" 5 .

Portanto, isto cria um continuum entre a oralidade e a escrita, inseparável do dialogismo inerente ao texto literário, tal como Bakhtin (1978) o definiu a partir da heteroglossia própria ao romance moderno.

\section{O romance plurilingue}

$\mathrm{Na}$ nossa opinião, o romance plurilingue comporta diferentes características que são as seguintes: um forte apego à realidade, marcas autobiográficas e a presença do tema do exílio ligado à questão da alteridade. No que diz respeito à escrita autobiográfica, esta permite a criação de um novo eu. Desta forma, misturadas as experiências do real vivido e os sentimentos sofridos, o testemunho e a memória misturamse e fundem-se num todo. Muitas vezes, o romance é contado na primeira pessoa por um narrador-autor. Assim, os escritores exilados são seres de fronteira e a sua escrita compreende a sua condição de dualidade: por um lado, a função referencial expressa nos factos reais e, por outro lado, a função poética expressa em suas obras.

Além disso, a leitura desses romances não é nem imediata nem consensual e esta literatura - escrita por quem viveu ou a experiência da migração ou a experiência da guerra colonial - é investida pela função de denúncia e de alerta contra o esquecimento. Os sujeitosnarradores encontram-se na sua condição de estrangeiros, perante si-próprios e os outros. Assim, somos confrontados com romances

5. «La littérature est la réalisation maximale de l'oralité, elle l'est chaque fois qu'elle s'accomplit comme une subjectivation maximale du discours ». 
que problematizam a crise de reconhecimento do ser pessoal e do ser Português. Desta forma, esta literatura espelha permanentemente o Outro. Essa literatura "nova" estabeleceu ruturas a nível da linguagem, incorporando marcas de alteridade por meio de processos linguísticos que revelam o plurilinguismo.

Os autores, de uma maneira ou de outra, afastaram-se do centro (Portugal) para se aproximarem de uma periferia (África ou Europa). Os autores que vivem entre diferentes culturas (Europa, África) desenvolvem, necessariamente, uma sensibilidade especial para com os outros e produzem uma literatura profundamente relacionada com a miscigenação de culturas. A miscigenação diz respeito, de facto, às diferentes representações de interação com o Outro (o estrangeiro, o nativo, o imigrante, o exilado) e a miscigenação cultural é, assim, compreendida nas suas dimensões cultural e ideológica, metafórica e pragmática. Note-se que Homi Bhabha (1994) expandiu significativamente a questão da miscigenação e permitiu que os estudos pós-coloniais se juntassem às preocupações do pós-modernismo, ou seja, às questões identitárias, às pertenças plurais, às diásporas, aos nacionalismos e aos movimentos transnacionais. Julia Kristeva (1997) liga a estranheza do migrante à do escritor, porque, segundo ela, o escritor vive um "exílio interior" e tem de se apropriar da sua (nova) língua de escrita. Nancy Huston (1999) salienta que o fenómeno da expatriação permite uma maior consciência linguística que é propícia à escrita. Não há dúvida de que o século XX corresponde a "extraterritorialidade" do escritor (ver Steiner, 1972) onde a literatura contemporânea é assinada por um exílio real ou psíquico, o que permite a Paul Ricoeur (2004: 17) aproximar a língua materna da língua estrangeira: "A ambição de descentralizar a língua materna, convidada a ser pensada como uma língua tal como as outras e, quase, a considerar-se ela própria como estrangeira" ${ }^{6}$.

A escrita permite, por um lado, estar ciente de que a sua língua não é única, e que, por outro lado, faz parte de uma infinidade de

6. «L'ambition de déprovincialiser la langue maternelle, invitée à se penser comme une langue parmi d'autres et, à la limite, à se percevoir elle-même comme étrangère ». 
línguas. A escrita participa da consciência da universalidade da linguagem, mas também da literatura. A escrita permite encarar o Outro e o que é diferente. A ideia de diferença - oposta à de unidade (unidade desejada durante a ditadura em Portugal) - está inserida no plurilinguismo e é, provavelmente, um dos traços enunciativos mais importantes. Podemos, desta forma, perguntarmo-nos como o híbrido é representado nesta literatura e como ela própria se torna um fator de miscigenação, até mesmo um verdadeiro suporte miscigenado (ver Turgeon, 2002).

\section{Hibridismo e miscigenação}

Focaremos a nossa atenção na especificidade da miscigenação literária dentro da miscigenação cultural. A mistura de culturas ocorre assim através de um confronto linguístico que afeta a língua portuguesa: o autor inclui no seu texto elementos linguísticos heterogéneos. A obra híbrida é interessante na medida em que não se limita a um género pré-determinado. Auerbach (1968) aproxima o realismo à mistura de géneros e define o romance como híbrido de estilos e de linguagens.

A noção de miscigenação, que inclui várias áreas e realidades, tanto em termos de cultura como em termos de linguística, une o conceito de hibridismo que foi desenvolvido principalmente por Bakhtin. O autor usa o conceito de hibridismo para descrever um dos conceitos-chave da sua teoria sobre a linguagem no romance. Não vê a literatura como um sistema unitário e homogéneo. A heteroglossia, ou seja, a coexistência, numa dada sociedade num dado momento, de uma multiplicidade de dialetos sociais e profissionais, estilos e géneros de retórica, constitui a realidade e a vida da linguagem. O romance é o lugar por excelência de uma polifonia que explora a heteroglossia da sociedade. Na verdade, qualquer romance cria um diálogo entre diferentes dialetos, integrando-os num projeto artístico.

O enunciado híbrido é, portanto, um processo de articulação de diferentes discursos pelos quais o romancista pode criar a polifonia no seio do seu texto, aparentemente unitário. Bakhtin (1978: 125- 
126) chama a este processo "construção híbrida": "Descrevemos o enunciado híbrido um enunciado que, de acordo com as suas pistas gramaticais (sintáticas) e composicionais, pertence exclusivamente ao locutor, mas no qual na verdade se misturam dois enunciados, duas maneiras de falar, dois estilos, duas "línguas", duas perspectivas semânticas e sociológicas"7.

O plurilinguismo literário, ou mais especificamente a enunciação em língua estrangeira, corresponde a uma palavra, uma frase ou uma passagem inteira que pertence a uma outra língua e que se insere no romance. A língua estrangeira é um elemento textual, entre outros, que espelha a relação entre identidade e alteridade nas áreas de alienação a que dizem respeito, nomeadamente ao exílio. A língua estrangeira pode fazer parte de um estratagema, de uma maneira de se singularizar ou de se destacar culturalmente ou pode ser usado para criar efeitos literários poéticos, quer de deslocação, quer de dessemantização. Se estas expressões não são traduzidas é porque os autores visam um efeito específico de enunciação ou porque não existe equivalente português do termo estrangeiro. A heterogeneidade dos romances é produzida por uma miscigenação de palavras estrangeiras. Os autores que usam de maneira abundante termos oriundos de diferentes línguas, também fazem uso de citações e de referências em língua estrangeira. O discurso do Outro tem como base um princípio de alteridade radical, de heterogeneidade irredutível e de exterioridade que inclui também a dos autores.

O propósito da nossa análise é o de compreender o que os diálogos podem trazer aos romances. Na verdade, não é a mesma coisa inserir uma personagem de ficção a falar numa língua estrangeira ou na sua língua nacional, como o indica Rosset (1992: 69),

As personagens de romance não sendo pessoas, o seu questionamento é menos sobre si próprio do que sobre o universo romanesco que as abriga. Quando uma personagem se interroga, é o romance enquanto

7. « Nous qualifions de construction hybride un énoncé qui, d'après ses indices grammaticaux (syntaxiques) et compositionnels, appartient au seul locuteur, mais où se confondent en réalité deux énoncés, deux manières de parler, deux styles, deux «langues», deux perspectives sémantiques et sociologiques ». 
espaço da representação que é designado. É por isso que o tema da língua estrangeira refere-se menos a ele próprio do que à construção do enredo, ao estatuto real e ao estatuto da língua por si próprio, ao sentido da fábula e aos desafios mais graves na edificação da ficção ${ }^{8}$.

Somos da opinião de que os discursos bilingues participam do realismo formal do romance e permitem isolar e distanciar as personagens dos narradores. As mudanças de língua ocorrem, mais frequentemente, quando há mudança de locutor durante o diálogo.

\section{Personagens africanas e plurilinguismo}

No que diz repeito aos romances ligados à guerra colonial, assistimos a duas vertentes aparentemente contraditórias no que diz respeito aos discursos de personagens africanas.

Em primeiro lugar, em romances nacionalistas ou nostálgicos, como os de António de Cértima (1970), ou de Wanda Ramos (1981), a presença de personagens africanas nos diálogos faz com que estes possam ser vistos como discursos de "pequeno português", uma vez que os africanos são retratados como personagens que falam um português muito sucinto, à maneira de nativos analfabetos, como o podemos ver nos seguintes excertos:

(1) - Ser aqui - disse o corpulento maconde, e retirou-se. - Bô noite! (António de Cértima, Não quero ser herói, p.110)

(2) - Minina trazer coisa linda p'ra Sinhor. (António de Cértima, Não quero ser herói, p.166)

8. «Les personnages de roman n’étant pas des personnes, leur questionnement porte moins sur eux-mêmes que sur 1'univers romanesque qui les abrite. Quand un personnage s'interroge, $c^{\prime}$ est le roman en tant qu'espace de la représentation qui est désigné. $\mathrm{C}^{\prime}$ est pourquoi le thème de la langue étrangère se réfère moins à luimême qu'à la construction de la trame, au statut du réel et à celui de la langue en soi, au sens de la fable et aux enjeux les plus graves de l’édification de la fiction ». 
(3) Entretanto o criado foi ver quem era e voltou com esta mensagem inquietante: "Está ali sinhor com farda de militar... (António de Cértima, Não quero ser herói, p.250)

(4) Voz empastelando-se na intermitência de falar quioco e português, esquivando-se a contar vidas no quimbo, a família, os mexericos que ouvia dos tropas fingindo não entendê-los, ah sinhora, vid'aqui na cassamba muito pobre, gente ignorante, eles virem de dia no sôtô e à noite metidos com quibamda, branco não sabe tratar, é do feitiço sinhora (...) (Wanda Ramos, Percursos: do Luachimo ao Luena, p.16)

(...) o preto é diferente sinhora, quioco tem hábito que branco não entende e ri muito, a gente não gosta de ver ele rir por isso não conta nada, mas se sinhora quer ver mucamda vem no domingo ao quimbo, há festa no domingo, Frederico? Sim sinhora, haver dança e batuque o dia todo, o povo faz mucanda. (Wanda Ramos, Percursos: do Luachimo ao Luena, p.70)

(6) (...) compra minima, compra sinhô (...). (Wanda Ramos, Percursos: do Luachimo ao Luena, p.91)

Estas personagens africanas são trabalhadores domésticos ou vendedores de rua, e as suas falas, representadas pelos narradores, parecem mostrar-nos um povo africano submetido, que domina mal a língua portuguesa, um povo primitivo cujo acesso à língua portuguesa não é estabelecido por completo. Isto permite pensar nos papéis hierárquicos e sociais da época colonial em África. Na verdade, estes diferentes trechos permitem ilustrar a superioridade social e hierárquica do colonizador e a extrema deferência das personagens (especialmente através das formas de tratamento). Estes diálogos contribuem para a encenação ficcional das práticas de língua entre africanos e colonos brancos, que, na era colonial, eram bastante limitadas. As personagens 
estão aqui em luta constante com as suas faces (negativa e positiva) que parecem ser condicionadas pelo seu status social (Ver a esse propósito a "teoria das faces" de Goffman, 1973). Para compensar esse facto, são obrigados a produzir atos ameaçadores ou lisonjeadores perante as faces dos seus alocutários (Ver Marques, 2007).

No entanto, romances escritos por autores de origem portuguesa como José Luandino Vieira durante a época colonial, têm valores semânticos muito diferentes. Nos seus romances o autor angolano confronta as faces contraditórias da sociedade colonial (racismo, guerra, miséria, exploração, luta nacionalista) expressando-se através de uma literatura nova que procura uma linguagem capaz de expressar novas lutas e novas realidades.

A linguagem é assim reinventada pelo autor que usa um português fragmentado, alternado com termos oriundos do kimbundu, neologismos e construções metalinguísticas.

(7) - Sente, menina! Mu muhatu mu! Mbia! mu tunda uazele, mu tunda uaxikelela, mu tunda uakusuka..." (José Luandino Vieira, Luuanda, p.19)

(8) - Bom dia meus senhores! Nem uazekele kié-uazeka kiambote, nem nada, era só assim a outra maneira civilizada como ele dizia, mas também depois ficava na boa conversa de patrícios e, então, aí o quimbundo já podia se assentar no meio de todas palavras, ele até queria, porque para falar bem-bem português não podia, o exame da terceira é que estava lhe tirar agora e por isso não acreditava falar um português de toda a gente, só queria falar o mais superior. (José Luandino Vieira, Luuanda, p.44)

(9) Armas aos catembos, dizes: friu, riu, tiu, alfacinha de mentira, e se eu chegasse nos teus ouvidos e despertasse os genes da tua avó, segredasse:

-Mbumbu se iala bua mbote, ita mixoxo? (José Luandino Vieira, Nós, os do Makulusu, p.87) 
(10) -Vadio ! Só quer andar no quilapanga, na boavaiela e eu a matar-me a trabalhar para ele estudar !... (José Luandino Vieira, Nós, os do Makulusu, p.102)

(11) Onde as penas do tempo passado, pássaros quentes e soltos no firmamento da vida e o espanto do moço que quer lhe voltar o dinheiro? "Xié, xié, kolombí-kolombí, muhatu ua mundele, ua-ngi-uabela, kiuá, kiuá" - nunca serei a mulher do branco, não sabias. (José Luandino Vieira, Nós, os do Makulusu, p.137)

Essa nova linguagem destaca-se do português escrito e falado na época na metrópole e pelo então colonizador e pertence a um processo de desintegração e de hibridismo vivido e sentido pelo narrador-autor.

\section{Personagens migrantes e plurilinguismo}

A análise do discurso das personagens migrantes na nossa amostra destaca o modo de criação dos escritores que tentem recriar a adaptação linguística e cultural dos emigrantes na sua sociedade de acolhimento. Os emigrantes portugueses estão representados nos romances analisados como uma comunidade específica, centrada e culturalmente miscigenada. As interferências linguísticas passam por incompetência e essas variações são consideradas como minoritárias. O dialeto de contacto é um socioleto desvalorizado, mas também subversivo, introduzido por narradores que se afastam, deixando a palavra, nos diálogos, às personagens migrantes. A função expressiva passa em primeiro lugar, em detrimento da função informativa, correndo o risco de causar uma certa ilegibilidade nalguns leitores portugueses. Assistimos, portanto, a um desvio entre a realidade social dos emigrantes e a atitude depreciativa generalizada que leva a uma certa exclusão desses mesmos migrantes. 
(12) “chomagem" (chômage/ desemprego) :

Agora existe o problema da chomagem (...). (Nita Clímaco, $A$ salto, p.95)

(13) “foram desembuchados" (ont été débauchés/ foram despedidos)

"entreprisas" (entreprises/empresas)

"vacanças" (vacances/ férias)

Muitos dos que já aqui se encontravam, foram desembuchados e as entreprisas não admitem pessoal novo. Muitos portugueses partiram para vacanças em Portugal, e cá ficarão pelo menos até ao Natal. (Nita Clímaco, A salto, p.95)

(14) "malada" (malade/doente)

$\mathrm{O}$ verão passado estive malada, não fomos là-bas. Estive, estive muito malada. (Olga Gonçalves, Este verão o emigrante là-bas, p.201)

(15) "chercha" (chercher/ procurar)

Disseram-me que chercha apartamento. (Maria João Lehning, D'acordo, p.149)

(16) "alocações" (allocations/ subsídios)

Com o que se poupava com a cantina e com as aloc's complementares, abreviatura das prestações sociais (...) (José Pardete Ferreira, Paris, ir e voltar, p.57)

(17) "meter o beque" (mettre le bec/meter o nariz)

Ele encolheu os ombros volumosos: "Não te irrites. Não meto o beque na vida das pessoas. Mas alguém me disse que alguém te tinha visto no norte de África. (Nita Clímaco, A salto, p.71)

(18) "petit canão" (petit canon/copo pequeno)

Ela pediu um petit canão, e eu vi logo o que ela queria, 
pedi logo um copo pequeno, mas disse em português. (Olga Gonçalves, Este verão o emigrante là-bas, p.79)

Os autores transpuseram nas suas obras as interferências mais comuns e representativas desta comunidade linguística aos olhos dos leitores nacionais monolingues (e possivelmente bilingues), visto que as manifestações em code-mixing não estão traduzidas.

Esses discursos diretos são, na nossa opinião, uma transposição da miscigenação linguística e cultural dessas personagens, recriando a sua experiência de desapropriação e de renúncia, através da sua migração. De facto, a experiência da perda (do país e da língua) permite aos autores mostrar essas personagens como vivendo na margem, não só da sociedade como também da língua e expressar a tensão entre eles e o Outro. É o que os autores foram capazes de capturar e recriar, dando voz a um discurso misto e socialmente desvalorizado. Esta palavra múltipla, presente em diferentes romances, revela uma prática de escrita heterogénea e reveste um triplo desafio - linguístico, literário e cultural.

Vemos que não é particularmente a busca de autenticidade, mas sim da expressividade que é visada pelos escritores. As línguas contêm uma extensa rede de valores, de fantasias e de afetos. O discurso bilingue é, portanto, um terreno ideal para questionar as abordagens ligadas à identidade e ao contexto na análise das práticas de língua visto que uma das funções tradicionalmente atribuída ao bilinguismo é a de o vincular a uma pertença de grupo ou de cultura. Esta afirmação, aparentemente óbvia, é de facto suscetível de ter diversas interpretações, dependendo das visões que temos sobre a noção de identidade.

De facto, as mudanças de língua contribuem para a conceção global dos romances e influenciam os seus temas. Os autores são livres de escolher a língua das suas obras, podem criar a sua própria língua romanesca. Mudando de língua - como código linguístico - os escritores também mudam de público, porque a relação com a língua influencia necessariamente a forma e o conteúdo das obras literárias, e por isso sua a receção. Como o indica Gauvin (2007: 113), a escrita 
é um verdadeiro "ato de linguagem": "Mais do que simples modos de integração da oralidade na escrita, ou do que a representação mais ou menos mimética das linguagens sociais, revela-se assim o estatuto de uma literatura, a sua integração/definição dos códigos e toda uma reflexão sobre a natureza e o funcionamento do literário" 9.

A justaposição de vozes, de discursos, de citações e de empréstimos em língua estrangeira são constantemente intercalados na estrutura narrativa dos romances. Como o observa Dominique Combe (1995: 136-137), isto participa da polifonia romanesca: "A polifonia é o facto de um plurilinguismo em ação, mas ao contrário do bilinguismo, de tradução ou de auto-tradução, as línguas não se encontram mais de maneira sucessiva, mas sim de maneira simultânea no espaço do livro" ${ }^{10}$.

\section{Considerações finais}

Como vimos, desde o ponto de vista de sua dimensão discursiva, as línguas, não só enquanto códigos, mas como práticas sociais são instrumentos de desafios sócio-políticos, sócio-económicos e sócioculturais. A heterogeneidade discursiva acompanha a miscigenação identitária e cultural presente nos romances plurilingues. Esta escrita plurilingue, com fontes culturais e linguísticas diversas, permite a construção de uma "meta-narrativa identitária" (Bibeau, 1996) e chama a atenção para a noção de identidade linguística.

O plurilinguismo, presente nos romances, representa uma força centrífuga que permite descentrar e quebrar o discurso monolingue e centralizado do Estado Português. A presença de formas nãoprestigiadas da língua portuguesa (especialmente no que diz respeito

9. «Plus que de simples modes d'intégration de l'oralité dans l'écrit, ou que la représentation plus ou moins mimétique des langages sociaux, on dévoile ainsi le statut d'une littérature, son intégration/définition des codes et enfin toute une réflexion sur la nature et le fonctionnement du littéraire».

10. « La polyphonie est le fait d'un plurilinguisme en acte; mais à la différence du bilinguisme, de traduction ou d'auto-traduction, les langues s'y rencontrent non plus successivement, mais simultanément dans l'espace du livre ». 
às personagens migrantes e personagens africanas) pode servir como um meio de resistência contra discursos que menosprezam a língua, a raça, ou a identidade desses grupos considerados marginais e pode, também, reproduzir uma solidariedade local, mesmo que às vezes os narradores se distanciem das personagens. Encontramo-nos perante uma dialética do centro e da periferia. De facto, os romances são um exemplo da desconstrução de modelos identitários dominantes que retratam personagens, representando grupos étnicos periféricos.

A miscigenação e o hibridismo linguísticos são, portanto, o espelho de um discurso de libertação que se pretende democrático e popular e onde a língua é, por um lado, uma ferramenta (como elemento narrativo) e, por outro lado, um apoio à liberdade de expressão, tornando-se, assim, plurilingue e polifónica. O plurilinguismo tem como ponto de partida a funcionalidade social e pragmática da língua. A noção de plurilinguismo está, portanto, próxima das tradições em antropologia linguística que ligam língua e sociabilidade. O plurilinguismo - seja ele literário ou não - deve ser visto, principalmente, como uma construção social e um ato de comunicação.

Assim, consideramos que a palavra e os textos devem estar situados no seu contexto temporal, social, político e cultural. O plurilinguismo literário baseia-se, com base nos resultados da nossa análise, num plurilinguismo interindividual e social, para recriar as suas características, as suas funções e os seus valores.

O plurilinguismo nos romances não funciona apenas como uma mera encenação da palavra do Outro em oposição a uma língua específica que garanta a identidade do locutor, mas sim como um movimento de relativização dos critérios de pertença identitária. Segundo Ana Paula Coutinho Mendes (2008: 7-8), alguns autores portugueses representam vozes miscigenadas:

O estatuto semiperiférico de Portugal e da sua cultura contemporânea, assombrados por uma História simultânea de colonização e de emigração, "nação crioula" (de acordo com a fórmula do escritor angolano José Eduardo Agualusa), europeia e transatlântica, de poder e de submissão, gerou formas híbridas de realidade e de 
cultura, verbalizadas por algumas vozes mescigenadas (mas não necessariamente de autores mestiços no sentido genético do termo). Vários autores viveram e deram conta, durante o período colonial, de um exílio que era mais psicológico e cultural do que territorial ${ }^{11}$.

O plurilinguismo desafia os conceitos de identidade e alteridade. É nisso que a teoria de Bakhtin é baseada, onde o Outro é, simultaneamente, a sua própria identidade e alteridade. O dialogismo implica uma certa concepção do homem, onde o Outro desempenha um papel essencial na constituição do $E u$. Assim, o autor é esta exterioridade que permite ver o personagem como um todo, essa consciência que envolve por inteiro o personagem, esta unidade através da qual medimos as diferenças de um personagem em relação a outro personagem.

Finamente, os escritores mostram, assim, a sua consciência da literatura como prática de língua, ativa e singular. As línguas do romance tornam-se, assim, o lugar do constrangimento pela gestão da legibilidade, que é, como o indica Michel Beniamino (1999: 280-281) um «jeu permanent entre la transparence et l'opacité » (pt. Um jogo permanente entre transparência e opacidade). A literatura é, assim, tributária e beneficiária da pluralidade das línguas e o plurilinguismo está em parte ligado com uma especificidade da literatura e da cultura.

Recebido em: abril de 2012 Aprovado em: maio de 2012 isabelle@fl.uc.pt

11. «Le statut semi-périphérique du Portugal et de sa culture contemporaine, hanté par une Histoire simultanée de colonisation et d'émigration, «nation créole» (selon la formule de l'écrivain angolais José Eduardo Agualusa), européenne et transatlantique, de pouvoir et de soumission, a engendré des formes hybrides de réalité et de culture, verbalisées par quelques voix métisses (mais non nécessairement d'auteurs métis au sens génétique du terme). Nombre de ces auteurs ont vécu et rendu compte, durant la période coloniale, d'un exil qui était plus psychologique et culturel qu'à proprement parler territorial ». 


\section{Referências bibliográficas}

AUERBACH, E. Mimèsis. Paris: Gallimard, 1968.

BAKHTINE, M. Esthétique et Théorie du roman. Paris: Gallimard, 1978.

BARTHES, R. S/Z. Paris: Éditions du Seuil, 1970.

BENIAMINO, M. La Francophonie littéraire. Essai pour une théorie. Paris: L’Harmattan, 1999, p. 280-281.

BIBEAU, G. Une identité en fragments. Une lecture ethnocritique du roman québécois. In: Elbaz, M., Fortin, A., Laforest, G. (Dirs.) Les frontières de l'identité. Sainte Foy: Presses de 1'Université de Laval, 1996, p. 311-346.

BHABHA, H. K. Les lieux de la culture, Une théorie postcoloniale. Paris: Payot, 2007, (1 ${ }^{\mathrm{a}}$ ed. em inglês em 1994).

CAPINHA, G. Literatura e emigração: poetas emigrantes nos Estados de Massachusetts e Rhode Island. In: Sousa Santos, B. De Sousa, (Org.), Portugal: Um retrato singular. Porto: Afrontamento, 1993.

COMBE, D. Poétiques Francophones. Paris: Hachette, 1995.

COSTA, J. Martins Barra Da, Exílio e asilo: a questão portuguesa (19741996). Lisboa: Universidade Aberta, 1996.

CRAVO, A., HEITOR, J. Rebelo (Dirs.), Vozes dos emigrantes em França: Antologia poética bilingue anos 1960-1982. [S.N], 1983.

DELEUZE, G. Critique et clinique. Paris: Les Éditions de Minuit, 1983.

DERRIDA, J. Le Monolinguisme de l'autre ou La prothèse d'origine. Paris: Galilée, 1996.

GAUVIN, L. L'écrivain francophone à la croisée des langues. Paris: Khartala, 1997.

GAUVIN, L. (Dir.) Les langues du roman: du plurilinguisme comme stratégie textuelle. Montréal: Les Presses universitaires de Montréal, 1999.

GAUVIN, L. L'imaginaire des langues: du carnavalesque au baroque. Littérature, 121: 101-116, 2001.

GAUVIN, L. Autor in fabula: pérégrinisme et paratexte. In: Perrot-Corpet, D., Queffélec, C. (Eds.), Citer la langue de l'autre. Mots étrangers dans le roman, de Proust à W.G. Sebald. Lyon: Presses universitaires de Lyon, 2007. 
GLISSANT, Edouard. Traité du Tout-Monde. (Poétique IV). Paris: Gallimard, 1997.

GOFFMAN, E. La mise en scène de la vie quotidienne - Les relations en public. Paris: Les Éditions de Minuit, 1973, Tome 2.

HUSTON, N. Nord Perdu suivi de Douze France. Paris: Actes Sud, 1999.

KRISTEVA, J. L'autre langue ou traduire le sensible. Textuel, 32: 157-170, 1997.

MESCHONNIC, H. Poétique du traduire. Paris: Éditions Verdier, 1999.

MAINGUENEAU, D. Le discours littéraire, paratopie et scène d'énonciation. Paris: Armand Colin, 2004.

MARQUES, I. Simões, Quand les langues s’emmêlent: alternance, mélange, interférences dans l'expression de l'injonction dans le roman portugais d'Olga Gonçalves, Este Verão, o emigrante là-bas. In: Carreira, M. H. Araújo (Dir.), De la suggestion à l'injonction dans les langues romanes. Université Paris 8: Travaux Et Documents, 32, 2007, p. 297-315.

MARQUES, I. Simões, Le plurilinguisme dans le roman portugais contemporain (1963-1983): caractéristiques, configurations linguistiques et énonciatives, Tese de Doutoramento, Université Paris 8 - Universidade Nova de Lisboa, 2009.

a) MARQUES, I. Simões, Confrontation et plurilinguisme linguistique dans Nós, os do Makulusu de José Luandino Vieira. In: Clavaron Y., Dutel, J., Lévy, C. (Dirs.), L'Etrangeté des Langues, Publications de L'Université de SaintÉtienne, 2011, p. 321-331.

b) MARQUES, I. Simões, O passaporte interior ou a questão da marginalidade em Este Verão o emigrante là-bas d'Olga Gonçalves. Réel et imaginaire dans l'espace lusophone, Revue Latitudes Cahiers Lusophones, 40: 3-7, 2011.

c) MARQUES, I. Simões, Autour de la question du plurilinguisme littéraire. La textualisation des langues dans les écritures francophones. Les Cahiers du Grelcef, 2: 227-244, 2011.

MACHADO, A. M. A geração de 70: Uma literatura de exílio. Análise Social, 61-62: 383-398, 1980.

MENDES, Ana Paula Coutinho, Corps d'exil. Quelques configurations chez des auteurs Portugais ou d'ascendance portugaise. Actes du Colloque international Temporalités de l'exil In: Http://Www.Poexil.Umontreal.Ca/ Events/Colloquetemp/Actes/Coutinho.Pdf 
MESCHONNIC, H. Poétique du traduire. Paris: Éditions Verdier, 1999.

RICCEUR, P. Sur la traduction. Paris: Bayard, 2004.

ROCHA-TRINDADE, M. B. Emigração Portuguesa: Os reflexos na origem. In: Ferreira, V. W. (Org.), Portugal 45-95, nas artes, nas letras e nas ideias. Lisboa: Centro Nacional de Cultura, 1998, p. 287-307.

ROSSET, F. L'Apprentissage des langues dans le roman français. Poétique, 89: 59-70, 1992.

SARAIVA, A. Bilinguismo e literatura. Porto: [S.N], 1977.

SEABRA, J. A. Manuel Alegre: da pátria exílio ao exílio da pátria. Das artes das letras, 18: 2-4, 2002.

SOARES, M. Escritos do exílio. Lisboa: Bertrand, 1975.

STEINER, G. Extratérritorialité, Essai sur la littérature et la révolution du langage. Paris: Hachette Littératures, 2003 ( $1^{\mathrm{a}}$ ed. em inglês em 1968).

TURGEON, L. Regards croisés sur le métissage. Québec: Celat- Université de Laval, 2002.

\section{Corpus literário}

CÉRTIMA, A. de. Não quero ser herói. Lisboa: Parceria A. M. Pereira, 1970. CLÍMACO, N. A salto. Lisboa: edição da autora, 1967.

GONÇALVES, O. Este verão o emigrante là-bas. Lisboa: Livraria Bertrand, 1978.

FERREIRA, J. P. Paris - ir e voltar. Lisboa: Prefácio, 2007.

LEHNING, M. J. D’acordo.Lisboa: Editorial Presença, 2003.

RAMOS, W. Percursos: do Luachimo ao Luena. Lisboa: Presença, 1981.

VIEIRA, J. L. Nós, os do Makulusu. Lisboa: Editorial Caminho, $2004\left(1^{\mathrm{a}} \mathrm{ed}\right.$. Sá da Costa, 1974).

VIEIRA, J. L. Luuanda: estórias. Lisboa: Editorial Caminho, 2004 (1 $1^{\mathrm{a}}$ ed. Edições 70, 1963). 